\title{
Dr. Catherine Hamlin: humble humanitarian, distinguished surgeon and 2014 Nobel Peace Prize nominee
}

\author{
Cheryl B. Iglesia, MD
}

Received: 27 September 2014 / Accepted: 3 October 2014 / Published online: 15 October 2014

(C) The International Urogynecological Association 2014

Many gynecologic surgeons and urogynecologists can look back on careers devoted to caring for women suffering from benign and malignant conditions of the reproductive organs and the pelvic floor. Some participate in short-term missions in developing countries, operating on a few patients with gynecologic disorders including fistulas. But it is the rare gynecologic surgeon who has devoted his or her entire career to caring for women in developing countries suffering from the plight of vesicovaginal and rectovaginal fistulas.

Dr. Catherine Hamlin, an Australian obstetrician-gynecologist, and her late husband, Reginald, answered an ad in the Lancet in 1958 to establish a midwifery school in Addis Ababa, Ethiopia. Touched by the physical and emotional suffering of obstetric fistula patients, they established the 120-bed Addis Ababa Fistula Hospital in 1974, and over the ensuing five decades also built five regional centers, and established the Hamlin College of Midwives and Desta Mender ("village of joy"), a "self-help" farm and training center for long-term patients. Dr. Hamlin turned 90 last January and her wish is to eradicate obstetric fistula by 2020 by focusing on prevention through a partnership with the Ethiopian government and the Hamlin foundation including an emphasis on the training of competent midwives to assist with antepartum, intrapartum and postpartum care throughout the country and with access to emergency obstetric services. Hamlin Fistula

C. B. Iglesia MD $(\bowtie)$

MedStar Washington Hospital Center and Georgetown University

School of Medicine, Washington, DC, USA

e-mail: cheryl.iglesia@medstar.net
Ethiopia (www.hamlinfistulausa.org) estimates that the cost of treating one fistula patient is 600 Australian dollars and the annual operating cost of the enterprise is $\$ 4.5$ million US dollars. To date, team Hamlin has treated more than 40,000 women with fistula and have been involved in over 10,000 safe deliveries through the midwifery rehabilitation team. Dr. Hamlin has clearly made a dent in the plight of women in Ethiopia where $85 \%$ of deliveries occur at home and with $10 \%$ of women enduring complications, half of which are related to prolonged labor.

According to the Ethiopian Federal Ministry of Health there is a back-log of over 30,000 women with fistula in Ethiopia and the immediate plan is to work with government extension workers to increase resources to treat these women and with plans to prevent future cases through education and training of midwives at over 330 health centers. The Hamlin fistula technique has been perfected and the program boasts greater than $90 \%$ cure rates with a significant improvement in the quality of these women's lives allowing them to reintegrate into society and restoring their dignity and self-worth. When asked how she started doing complex fistula work in the 1960s, Dr. Hamlin said, "We started with small fistulas which any gynaecologist can fix without much training, and gradually tackled more difficult ones" [1]. She refined techniques adapted from gynecologists, urologists and other international surgical experts in Egypt, India and other countries. Admittedly, there are challenges in Ethiopia related to communication, access to clean water, necessary drugs and supplies as well as qualified mentors in the training program. Globally, there are over 3 million women worldwide with fistula with estimates of $50-100,000$ new fistula cases per year. 
In March 2014, Dr. Hamlin was awarded the Society of Gynecologic Surgeons (SGS) Distinguished Surgeon award by Dr. Holly Richter, President of SGS, at its annual meeting in Scottsdale, Arizona. Dr. Hamlin is the second female surgeon to win this prestigious prize since it was first awarded in 1985. Dr. Senait Fisseha, Associate Professor of Obstetrics, Gynecology and Chief, Division of Reproductive Endocrinology and Infertility at University of Michigan, accepted the award on Dr. Hamlin's behalf. In a videotaped acceptance speech, Dr. Hamlin said, "I am very grateful for this award because it will bring help to the women of this country suffering from vesicovaginal fistula. I just want to draw the attention of the world to this great need here for maternal health... The world has forgotten these women...Before I die, and I am 90 now...I want to help these women. I know you would all be touched if you could see them in their plight... but to see them go home with a new outlook... and on dancing feet gives us all the joy we need to do this work."

Indeed, the world needs more surgeons and physicians like Dr. Hamlin. She has been nominated for the 2014 Nobel Peace Prize and although the prize was awarded to children's rights activists Malala Yousafzai from Pakistan and Kailash Satyarthi of India, Dr. Hamlin's legacy lives on,an her efforts will most certainly bring attention to these women in need in Ethiopia and around the world. Go on, Dr. Hamlin Photo credit: Joni Kabana

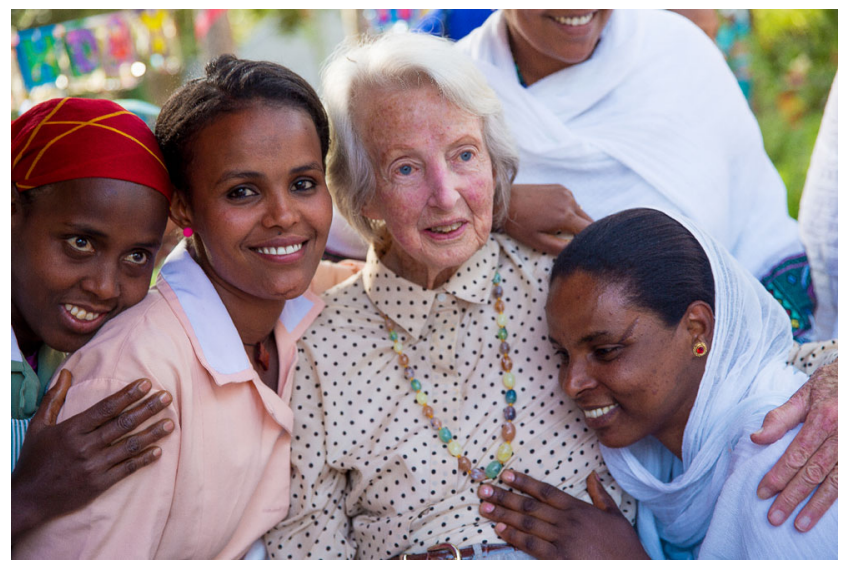

\section{References}

1. Hamlin C, Fleck F (2013) Giving hope to rural women with obstetric fistula in Ethiopia. Bull World Health Organ 91(10):724-725. doi:10. 2471/BLT.13.031013 